\title{
Synthesis and Characterization of Agglomerated Coarse Al Powders Comprising Nanoparticles by Low Energy Ball Milling Process
}

\author{
Nusia Eom ${ }^{1}$, Mahedi Hasan Bhuiyan ${ }^{1}$, Taek-Soo Kim ${ }^{2}$ and Soon-Jik Hong ${ }^{1, *}$ \\ ${ }^{1}$ Division of Advanced Materials Engineering and Institute for Rare Metals, Kongju National University, \\ 275, Budae-dong, Cheonan City, Chungcheongnam-do, 330-717, Korea \\ ${ }^{2}$ Korea Institute of Industrial Technology (KITECH), 7-47, Songdo-dong, Yeonsu-Gu, Incheon 406-840, Korea
}

\begin{abstract}
Agglomerated coarse $\mathrm{Al}$ powders consisting of nanoparticles were synthesized by low energy ball milling process, and subsequently their structures were characterized in terms of agglomeration size, shape, and porosity depending on various milling time, ball size, and ball to powder weight ratio in order to optimize the process parameters. A higher milling time caused a decrease in the agglomeration size and their shape tends to become spherical while reducing the pore sizes. The agglomeration size was also reduced as the ball to powder weight ratio increased and the ball size decreased. The partial cold welding of the nanoparticles at lower milling time and fully cold welding of the nanoparticles at higher milling time were correspondingly responsible to produce larger and smaller agglomerations, respectively.
\end{abstract}

[doi:10.2320/matertrans.M2011059]

(Received February 18, 2011; Accepted May 23, 2011; Published July 6, 2011)

Keywords: powder agglomeration, nanoparticle, low energy ball milling, cold welding

\section{Introduction}

The nano-aluminum powder possessing a greater specific surface area exhibits unique properties and reveals reactivity parameters better than those for micron-sized Al powders, which has recently drawn the attention of researchers all over the world. ${ }^{1)}$ On the other hand, the demand of porous material is gradually emerging due to technological advancement of many applications such as energy conversion and storage, environment friendly catalysis, sensors, drug delivery, medical diagnosis, cell makers and photonics ${ }^{2,3)}$ as it offers an enhanced interaction between the atoms, ions and molecules, turning it to deliver superior properties. Therefore, the synthesis of nano- and porous $\mathrm{Al}$ powder is of great interest, and a lot of techniques such as pulsed wire evaporation (PWE $)^{4,5)}$ and mechanical alloying ${ }^{6-8)}$ have been previously employed to manufacture $\mathrm{Al}$ nanopowders along with nanocrystalline and amorphous composites ${ }^{9-11)}$ through powder metallurgy route for tailoring their structures with desired properties.

Out of the above mentioned nanopowder synthesizing methods, ball milling process is one of the favorable solid state nanopowder fabrication technique featured with economical and simple operations for mass production. ${ }^{12)}$ Other studies have reported evidences of milling processess applied on conventional powders, in order to explain powder behavior and formation of equilibrium phase during milling. However, studies related to mechanical milling operations on Al nanopowder, especially to analyze the size, shape and milling behavior are very rare.

Consequently, in this research, agglomerated coarse $\mathrm{Al}$ powders having porous structures constituted by nanoparticles were synthesized using low energy ball milling process, and the effects of various processing parameters like milling time, ball size and ball to powder weight ratio on the resultant powder's morphology, agglomeration tendency, size and porosity were investigated.

*Corresponding author, E-mail: hongsj@kongju.ac.kr

\section{Experimental Procedure}

High purity (with greater than 99.9\%), partially agglomerated spherical Al powder with mean size $100 \mathrm{~nm}$ was used in the present study, and the milling process was performed in a low energy ball mill (BML-2) having stainless steel jar $(4.8 \mathrm{~cm}$ diameter $\times 11.9 \mathrm{~cm}$ height $)$ and balls, while maintaining the rotational speed at $400 \mathrm{rpm}$. The nanopowders were produced using pulsed wire explosion from initial $0.5 \mathrm{~mm}$ thickness $\mathrm{Al}$ wire in an argon atmosphere at $0.1 \mathrm{MPa}$ pressure. In order to understand the process optimization, a variety in ball size of $4.70 \mathrm{~mm}, 5.54 \mathrm{~mm}$ and $7.20 \mathrm{~mm}$ and ball to powder weight ratio of $10: 1,15: 1$ and $20: 1$ were employed during the milling process for $10 \mathrm{~min}, 30 \mathrm{~min}$ and $60 \mathrm{~min}$. Stearic acid $\left(\mathrm{C}_{18} \mathrm{H}_{36} \mathrm{O}_{2}\right)$ was added into the powders as a process control agent to prevent excessive agglomeration of the powders during milling process. The size distribution of the as-milled powder was carried out by laser diffraction technique using Mastersizer 2000 particle size analyzer. The morphologies, microstructure and porosity of the powders were observed and analyzed by scanning electron microscopy (SEM) and transmission electron microscopy (TEM).

\section{Results and Discussion}

Figures 1(a) and (b) show the SEM micrographs of the non milled powders $(\sim 100 \mathrm{~nm})$, while the variation in the morphologies and structures of the ball milled powders depending on the milling time and ball to powder weight ratio are exhibited in Fig. 2 for a ball size of $5.54 \mathrm{~mm}$ with inset micrographs showing in higher magnification. It can be clearly seen in Fig. 1(a) that non agglomerated, non milled, nanosized powders can exist, while they can as well illustrate a partially agglomerated state as shown in Fig. 1(b). In general, the agglomeration size reduces as the milling time increases, and a higher ball to powder ratio produces not only smaller but also uniform and spherical shaped agglomerations with increased porosity (inset micrograph) as delineated in Fig. 2. The milling process with a ball to powder weight 

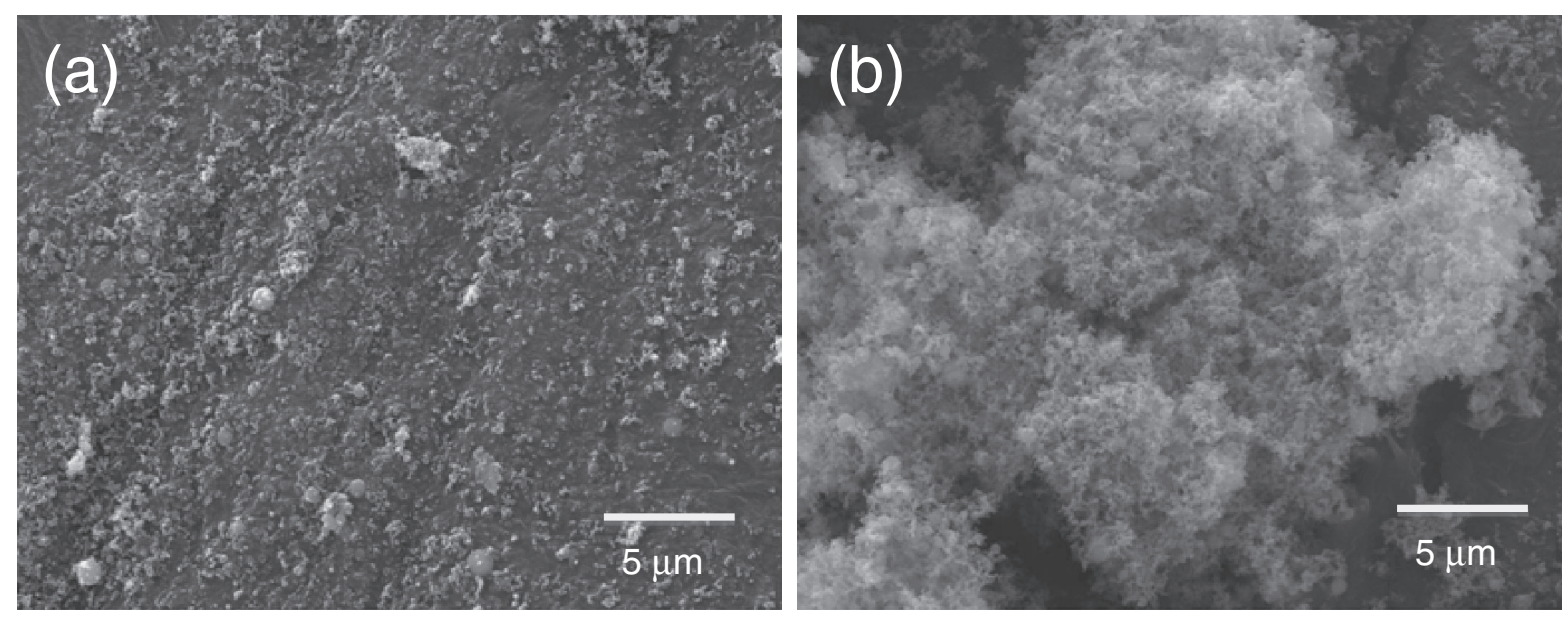

Fig. 1 SEM Micrograph of the non milled Al powders; (a) distributed powders, (b) agglomerated powders.

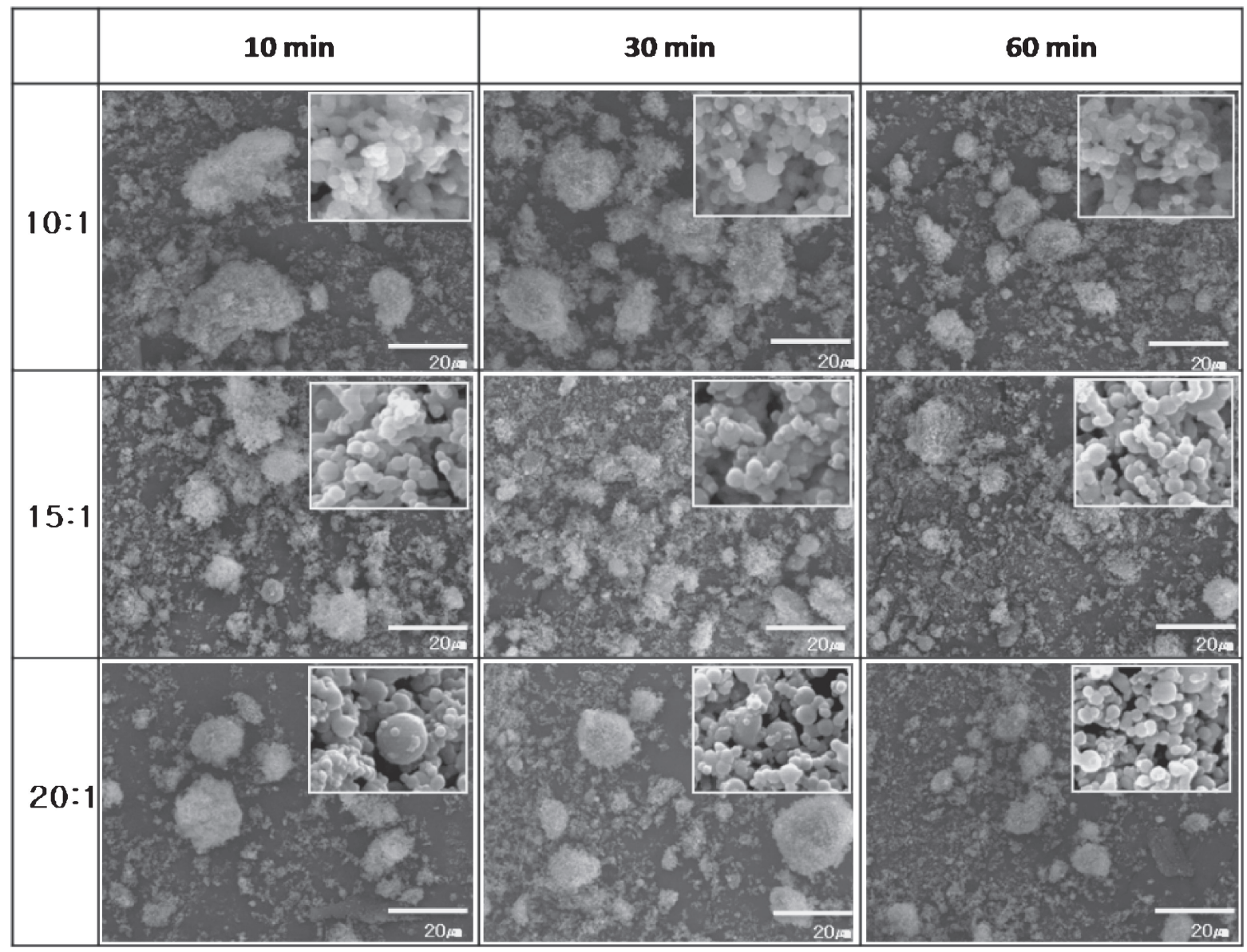

Fig. 2 SEM Micrographs of milled Al nanopowders for various milling time and ball to powder weight ratio with ball size of 5.54 mm.

ratio of $10: 1$ for $10 \mathrm{~min}$ results in a bit elongated large agglomeration having approximately $31 \mu \mathrm{m}$ in size, which becomes $19 \mu \mathrm{m}$ and $11 \mu \mathrm{m}$ sphere as the milling time advances to $30 \mathrm{~min}$ and $60 \mathrm{~min}$, respectively. Likewise, an increase in the ball to powder weight ratio from $10: 1$ to $20: 1$ also resulted in reduced agglomeration from $31 \mu \mathrm{m}$ to $17 \mu \mathrm{m}$, respectively. The morphology of these coarse powders is more conspicuous at a higher magnification as represented in Fig. 3 for a ball to powder weight ratio of $15: 1$ and ball size of $5.54 \mathrm{~mm}$. It reveals that all of these agglomerated powders consist of strongly bonded spherical nanopowders with porous structures as marked by arrows in the figures. During milling process, continuous cold-welding and fracture of the powder particle takes place caused by shear forces between the balls, powders and jar wall. As the milling process advances, the smaller nanopowders make bonding between themselves due to cold welding, turning it to become porous and agglomerated coarse powders. Besides, for a constant ball size (i.e. $5.54 \mathrm{~mm}$ ) during the process, an increase in the ball to powder weight ratio means 

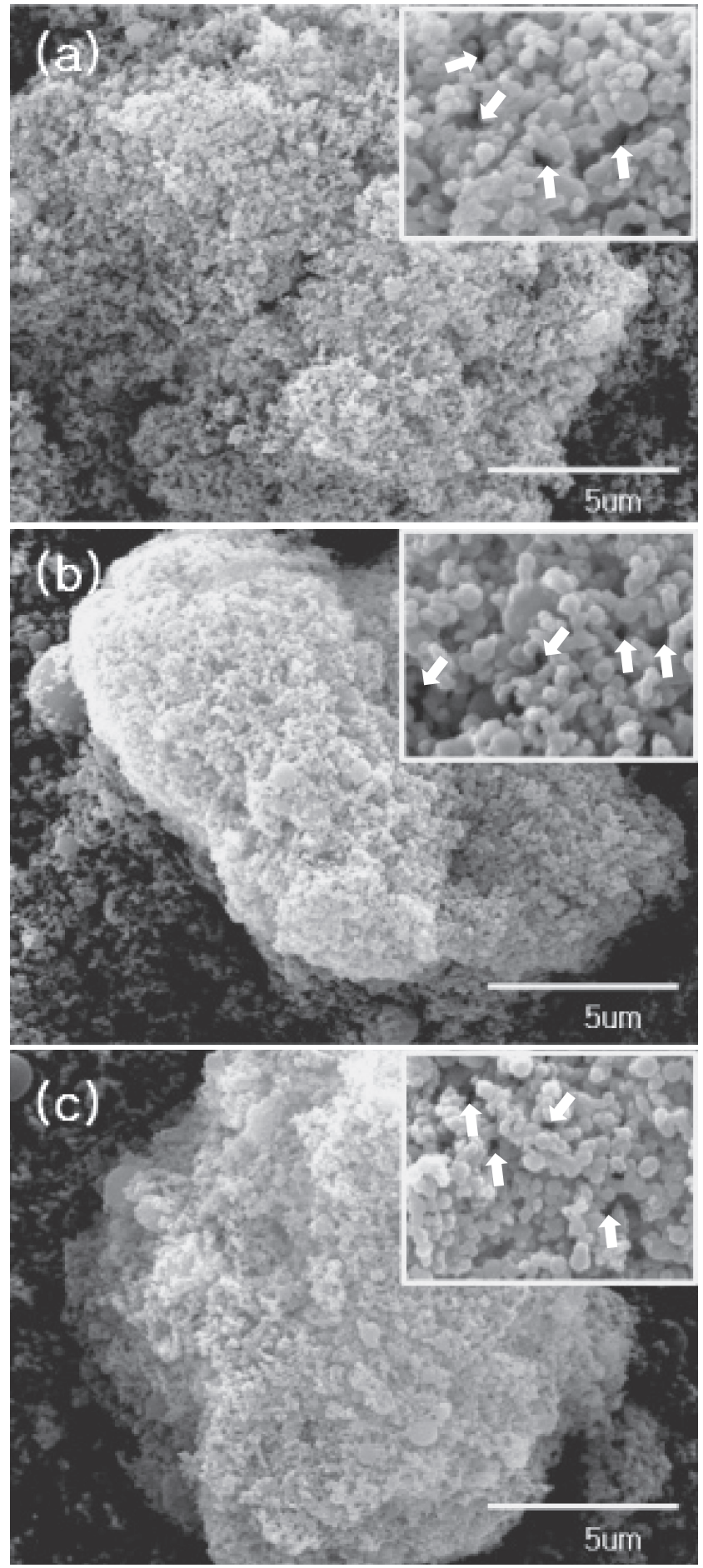

Fig. 3 A higher magnification micrograph of the milled Al nanopowders for milling time of (a) $10 \mathrm{~min}$, (b) $30 \mathrm{~min}$ and (c) $60 \mathrm{~min}$ with ball size of $5.54 \mathrm{~mm}$ and ball to powder ratio of $15: 1$.

a greater number of balls are in use. Thus a greater collision rate and greater shear force is attained, resulting in higher fragmentation rate of the agglomerations than cold welding of the nanoparticles causing to decrease the agglomeration size.

Figure 4 illustrates size distribution of the as milled powders with different milling conditions. It appears that the mean size of the agglomerated powders linearly grew up to a milling time of $10 \mathrm{~min}$, peaked at approximately $15 \mathrm{~min}$, and
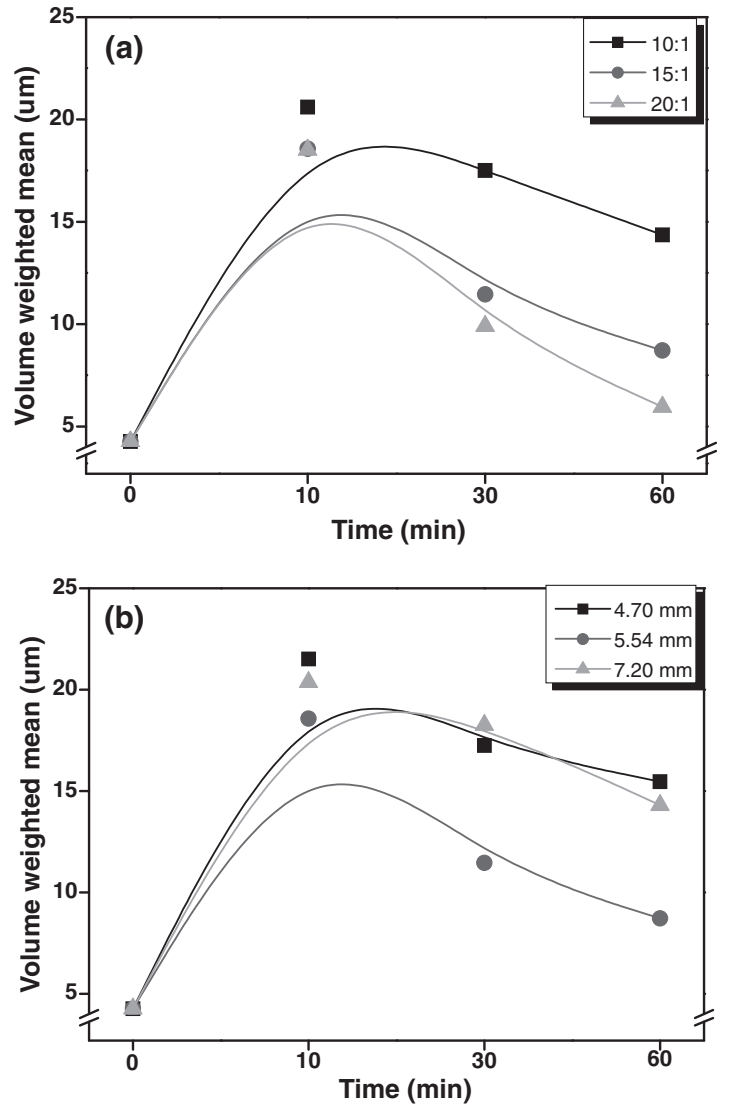

Fig. 4 Variation in the mean particle size with the milling time for different (a) ball to powder weight ratio (ball size $5.54 \mathrm{~mm}$ ) and (b) ball size (ball : powder $=15: 1$ ).

then gradually dropped as the milling time increased to $30 \mathrm{~min}$ and $60 \mathrm{~min}$. At the earlier stage of milling, the rate of mechanical bonding caused by plastic deformation of the powders becomes higher than the fragmentation due to higher rate of cold welding. As the milling process continues, the powders become work hardened, thus easily allowing them to initiate crack and growth under stress cycles. At the later stages fracture of the cold welded powders takes place at a higher rate causing to reduce the mean particle sizes. In addition, an increase in the ball to powder weight ratio lowers the mean particle size as shown in Fig. 4(a), which is in well agreement with Fig. 2. Moreover, the effect of various ball sizes on the resultant ball milled powder for a ball to powder weight ratio of $15: 1$ was also studied in this research and their size distribution are shown in Fig. 4(b). The quantitative values with variations in particle size for different ball size and milling time is presented in Table 1, while Table 2 shows the quantitative changes in particle size with milling time and ball to powder ratio. Apparently, for each ball size, varying from $4.70 \mathrm{~mm}$ to $7.20 \mathrm{~mm}$, agglomeration size reduced as milling time increased, while porosity showed an almost similar behavior with slight variation. For $15: 1$ ball to powder weight ration, total pore volume was found to be around $0.0466 \mathrm{~cm}^{3} / \mathrm{g}$, where pore diameter was around $1.22 \mathrm{~nm}$ without many changes to it. It was seen that the mean particle size increased in the beginning of milling for all ball sizes up to $10 \mathrm{~min}$ and dropped in a uniform method in all cases, with $15: 1$ ball to powder weight ratio. Although the 
Table 1 Variation in particle size with milling time and ball size.

\begin{tabular}{|c|c|c|c|c|}
\hline \multirow{2}{*}{ Ball Size } & \multirow{2}{*}{$\begin{array}{c}\text { Particle size } \\
\text { range }\end{array}$} & \multicolumn{3}{|c|}{ Milling Time } \\
\hline & & $10 \min (\mu \mathrm{m})$ & $30 \min (\mu \mathrm{m})$ & $60 \min (\mu \mathrm{m})$ \\
\hline \multirow{2}{*}{$4.7 \Phi$} & $\mathrm{d}(0.1)$ & 1.521 & 0.849 & 0.685 \\
\hline & $\mathrm{d}(0.9)$ & 46.474 & 42.115 & 32.973 \\
\hline \multirow{2}{*}{$5.54 \Phi$} & $\mathrm{d}(0.1)$ & 1.197 & 0.741 & 0.592 \\
\hline & $\mathrm{d}(0.9)$ & 43.292 & 33.006 & 27.066 \\
\hline \multirow{2}{*}{$7.2 \Phi$} & $\mathrm{d}(0.1)$ & 1.322 & 0.785 & 0.66 \\
\hline & $\mathrm{d}(0.9)$ & 44.52 & 40.815 & 38.991 \\
\hline
\end{tabular}

Table 2 Variation in particle size with milling time and ball to powder ratio.

\begin{tabular}{cccccc}
\hline \multirow{2}{*}{ Ball : Powder } & $\begin{array}{c}\text { Particle size } \\
\text { range }\end{array}$ & & \multicolumn{3}{c}{ Milling Time } \\
\cline { 2 - 3 } $10: 1$ & $\mathrm{~d}(0.1)$ & & 1.569 & 1.062 & 0.709 \\
\cline { 2 - 2 } & $\mathrm{d}(0.9)$ & & 45.299 & 40.438 & 36.513 \\
\hline \multirow{2}{*}{$15: 1$} & $\mathrm{~d}(0.1)$ & & 1.197 & 0.741 & 0.592 \\
\cline { 2 - 2 } & $\mathrm{d}(0.9)$ & & 43.292 & 33.006 & 27.016 \\
\hline \multirow{2}{*}{$20: 1$} & $\mathrm{~d}(0.1)$ & & 1.127 & 0.655 & 0.56 \\
\cline { 2 - 2 } & $\mathrm{d}(0.9)$ & & 43.494 & 28.101 & 17.515 \\
\hline
\end{tabular}

progression and pattern was similar for all ball sizes, still $5.54 \mathrm{~mm}$ ball size managed to maintain the lowest average particle size compared to the other balls, with minor difference. However, an increase in the ball size resulted in further coarsening of the agglomerations without significantly affecting the porosity. This is particularly seen for $7.2 \mathrm{~mm}$ balls where larger agglomerated particles were observed, which would eventually break into coarser particles. This coarsening took place might be because of the less shear force acting on the powder particles. It is known that for a constant ball to powder weight ratio (i.e. 15 : 1); employing a larger ball size means less number of balls is in use. Thus the reduced surface area of the balls delivers less shear force on the powders. Though a larger ball size provides greater impact force and kinetic energy due to increased mass but it delivers lower collision rate causing to dominate the bonding mechanism over the fracture mechanism.

The nature and characteristics of the bonds between the nanopowders attained in the agglomerated porous powders are substantially dependent on the milling time as represented in the TEM micrographs of Fig. 5(a) and (b). It seems that at lower milling time (i.e. $10 \mathrm{~min}$ ), the powders are less coherent and a non-uniform large porosity could be observed (Fig. 5(a)). Higher magnification (Fig. 5(c)) reveals that these agglomerations are mostly formed by the partial cold welding of the nanoparticles due to less shear forces exerted on the nanoparticles. However, powders milled for longer time (i.e. $60 \mathrm{~min}$ ) as shown in Fig. 5(b), exhibits the presence of lower but uniform porosity within the densely agglomerated nanopowders corresponding to the fully cold welding of the nanoparticles (Fig. 5(d)) caused by repetitive shear forces. The mechanism, formation and evolution of agglomerated coarse $\mathrm{Al}$ powders comprising nanoparticles are

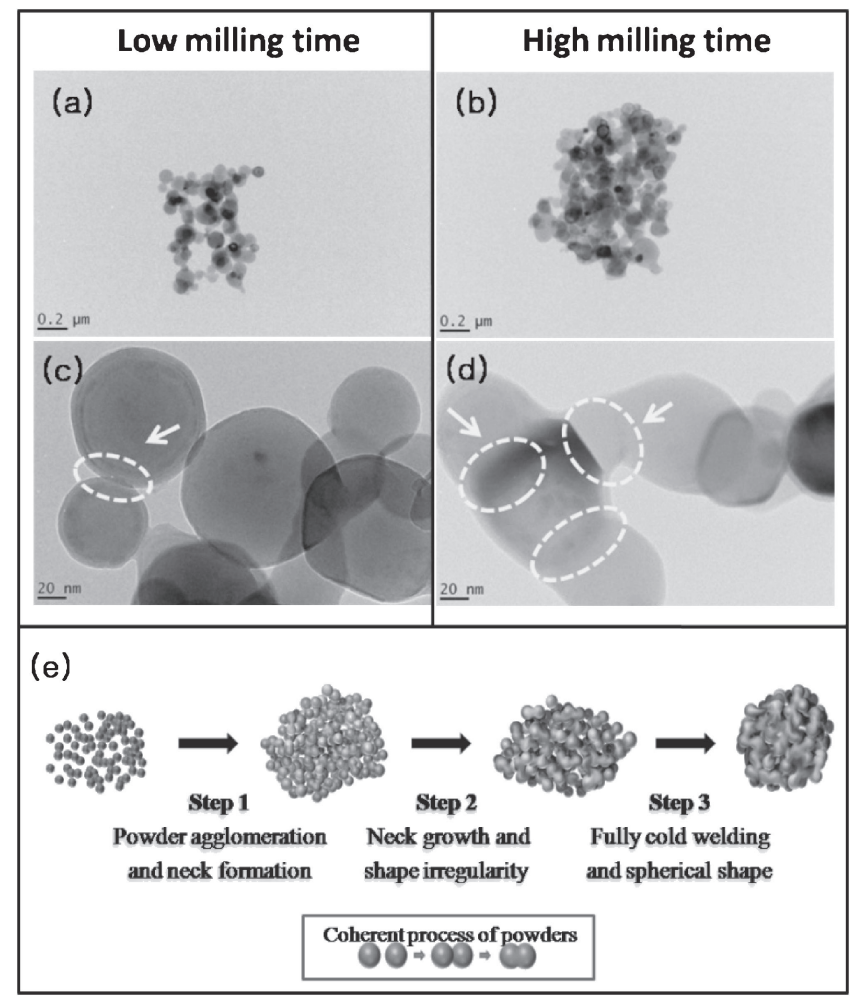

Fig. 5 TEM micrograph showing the bonding mechanism between the Al nanoparticles during milling process for ball size of $5.54 \mathrm{~mm}$ and ball to powder ratio of $15: 1$; (a) $10 \mathrm{~min}$ (b) $60 \mathrm{~min}$ (c) enlargement of $10 \mathrm{~min}$ photograph (d) enlargement of 60 min photograph and (e) Schematic diagram showing the formation of agglomerated coarse $\mathrm{Al}$ nanopowders during the low energy ball milling process.

demonstrated in the schematic diagram of Fig. 5(e). At the initial stage of milling process (step 1), the raw nanopowders becomes partially bonded by deformation and cold welding, resulting in the neck formation within the bonded region. This necking continues to grow proportionally with the milling time making the agglomeration shape irregular (step 2). And finally, at the later stage (step 3), the nanopowder becomes more coherent and fully bonded due to further growth of necking and continuous process of fracture and welding mechanism, transforming them into coarse and porous agglomerations. Hence, the above results indicate that the low energy ball milling process manifests a convenient method, and can be considered a promising technique to produce agglomerated coarse $\mathrm{Al}$ powders with varying size, shape and porosity comprising nanoparticles.

\section{Conclusion}

The low energy ball milling process was effective in synthesizing porous and agglomerated $\mathrm{Al}$ powders consisting of $60 \sim 120 \mathrm{~nm}$ sized spherical nanoparticles on average. A lower milling time resulted in larger agglomerations because of the higher rate of partial cold welding of the nanoparticles relative to its fragmentation, whereas a higher milling time yielded fully cold welding of the nanoparticles delivering smaller and completely spherical agglomerations. In addition, the higher the ball size was used during the milling process, the larger the agglomeration it exhibited without any 
considerable effect on the porosity. However, the agglomeration size decreased but the porosity increased as the ball to powder weight ratio increased resulting in more uniform and spherical coarse powders. The optimized process parameter was found to be a ball size of $4.70 \mathrm{~mm}$ and ball to powder weight ratio of $10: 1$ with $10 \mathrm{~min}$ milling time.

\section{Acknowledgment}

This research was supported by Basic Science Research Program through the National Research Foundation of Korea (NRF) funded by the Ministry of Education, Science and Technology (KRF-2008-331-D00746).

\section{REFERENCES}

1) R. Sarathi, T. K. Sindhu and S. R. Chakravarthy: Mater. Charact. 58 (2007) 148-155.
2) Y. Yang, Y. Wang, W. Tian, Z. Wang, C. Li, Y. Zhao and H. Bian: Scr Mater. 60 (2009) 578-581.

3) C. W. Guo, Y. Cao, S. H. Xie, W. L. Dai and K. N. Fan: Chem Commun. 6 (2003) 700-701.

4) G. H. Lee, J. H. Park, C. K. Rhee and W. W. Kim: J. Ind. Eng. Chem. 9 (2003) 71-75.

5) T. K. Sindhu, R. Sarathi and S. R. Chakravarthy: Bull. Mater. Sci. 30 (2007) 187-195.

6) F. Zhou, D. Witkin, S. R. Nutt and E. J. Lavernia: Mater. Sci. Eng. A 375-377 (2004) 917-921.

7) M. Cho, H. Choi, M. Asiam, J. Shin and D. Bae: Met. Mater. Int. 16 (2010) 67-70.

8) J. A. Rodriguez, J. M. Gallardo and E. J. Herrera: J. Mater. Sci. 32 (1997) 3535-3539.

9) M. A. Sheikh, M. Iqbal, J. I. Akhter, M. Ahmed, Q. Zaman, M. Akhtar, M. J. Moughal, Z. Ahmed and M. Farooque: Mater. Lett. 57 (2003) 3681-3685.

10) J. M. Wu: Mater. Lett. 48 (2001) 324-330.

11) M. Tavoosi, F. Karimzadeh and M. H. Enayati: Mater. Lett. 62 (2008) 282-285.

12) C. Suryanarayana: Prog. Mater. Sci. 46 (2001) 1-184. 